\title{
Полосковая структура для изорешеточных квантовых каскадных лазеров
}

\author{
(C) В.В. Мамутин, Н.Д. Ильинская, А.А. Усикова, А.В. Лютецкий \\ Физико-технический институт им. А.Ф. Иофрфе Российской академии наук, \\ 194021 Санкт-Петербург, Россия \\ E-mail: mamutin@mail.ru
}

(Получена 23 мая 2018г. Принята к печати 28 мая 2018 г.)

Описано получение и исследование гребневой полосковой структуры (ridge waveguide) для квантового каскадного лазера на подложке фосфида индия, рассчитанного на длину волны 4.8 мкм, что соответствует одному из окон прозрачности атмосферы. Гетероструктура была выращена молекулярно-пучковой эпитаксией и состояла из 30 каскадов. Постростовая обработка проводилась методом фотолитографии на отечественном оборудовании. Полученная полосковая структура позволила достичь лазерной генерации на требуемой длине волны при комнатной температуре.

DOI: $10.21883 /$ FTP.2018.12.46764.8916

\section{1. Введение}

Как известно, наибольшие трудности в получении квантовых каскадных лазеров (ККЛ) вызывает не сам рост структуры, хотя и он весьма сложен, а постростовой процесс приготовления качественного прибоpa [1]. Для работы ККЛ требуются гораздо большие, чем для обычного полупроводникового лазера, токи и напряжения, что приводит к сильному перегреву лазеров в рабочем диапазоне. Здесь актуальной, если не основной, становится система теплоотвода, которая ранее решалась различными способами: заращивание фосфидом индия с большим теплоотводом [2], напайка на материал с максимальной теплопроводностью, например алмаз [3], которые являются весьма трудоемкими и дорогостоящими процессами, усложненными привлечением сторонних технологий. Для ККЛ, работающих вблизи окон прозрачности атмосферы (3-5 мкм) в основном из-за технологичности, показателя преломления и подходящего теплоотвода, используются гетероструктуры со слоями InGaAs/AlInAs на подложках InP [1-4].

В данной работе мы исследовали изготовление и постростовую обработку изорешеточной с подложкой фосфида индия гетероструктуры, как наиболее точно контролируемой по составу слоев с помощью рентгеновской дифракции и фотолюминесценции. Напряженнокомпенсированные гетероструктуры требуют применения неоднозначно интерпретируемых моделей расчета кривых рентгеновской дифракции, в которых изменение толщин в модели приводит к изменению состава и наоборот. В случае изорешеточных сверхрешеток такая неоднозначность исключена ввиду четкого определения независимо от состава и толщин толстых слоев тестовых структур, полученных до роста лазерной структуры. Кроме того, этот диапазон составов слоев удобен и для получения толстых бездислокационных эмиттеров, необходимых в различных конкретных структурах квантовых каскадных лазеров.
В данной работе нами было проведено получение гребневой полосковой структуры (ridge waveguide) для излучающей на длине волны вблизи 4.8 мкм изорешеточной гетероструктуры ККЛ, выращенной методом молекулярно-пучковой эпитаксии (МПЭ) с целью улучшения теплоотвода и достижения лазерной генерации при комнатной температуре. В работе проводилось исследование постростовой обработки и характеристик полученной полосковой структуры с целью отработки на имеющемся в ФТИ им. А.Ф. Иоффе оборудовании необходимых операций для получения высококачественных приборов (ККЛ). Ранее нами на этой структуре без полосков была достигнута лазерная генерация только при температурах до $200 \mathrm{~K}$ [5].

\section{2. Эксперимент}

\section{1. Выращивание гетероструктур}

Лазерные гетероструктуры были выращены молекулярно-пучковой эпитаксией (MПЭ) на установке RIBER Compact-21 TM. Ростовые температуры активных областей лазерных структур составляли $500^{\circ} \mathrm{C}$, и при росте использовались слабо Аs-стабилизированные условия. Лазерная структура была разработана с решеточносогласованной активной областью и эмиттерами и наносилась на подложку $n$ - $\operatorname{InP}(100): \mathrm{Sn}$, легированную до $2 \cdot 10^{17} \mathrm{~cm}^{-3}$.

Активная область квантового каскадного лазера состояла из 30 периодов. Один период содержал последовательность из 18 чередующихся слоев AlInAs/GaInAs (B HM):

\section{$3.0 / \underline{4.0} / 2.2 / \underline{4.7} / 1.5 / \underline{0.9} / 5.0 / \underline{1.9} / 2.8 /$}

$$
\underline{1.9} / 2.3 / \underline{2.0} / \mathbf{2 . 0} / \underline{\mathbf{2 . 0}} / \mathbf{2 . 2} / \underline{\mathbf{2 . 2}} / 2.3 / \underline{2.3}
$$

с подчеркнутыми слоями квантовых ям GaInAs и выделенными (bold) легированными слоями. Они были легированы кремнием на уровне $n=4 \cdot 10^{17} \mathrm{~cm}^{-3}$. 
Вся структура (указана последовательность от подложки по направлению роста, в скобках приводится уровень легирования) состояла из следующих слоев: 300 нм волноводный слой $\mathrm{Ga}_{0.47} \mathrm{In}_{0.53} \mathrm{As}$ $\left(1 \cdot 10^{17} \mathrm{~cm}^{-3}\right), 1356$ нм (30 периодов) активная зона, 200 нм волноводный слой $\mathrm{Ga}_{0.47} \mathrm{In}_{0.53} \mathrm{As}\left(1 \cdot 10^{17} \mathrm{~cm}^{-3}\right)$, затем начинается толстый эмиттер: $600 \mathrm{HM} \mathrm{Al}_{0.48} \mathrm{In}_{0.52} \mathrm{As}$ $\left(2 \cdot 10^{17} \mathrm{~cm}^{-3}\right), \quad 700 \mathrm{HM} \quad \mathrm{Al}_{0.48} \mathrm{In}_{0.52} \mathrm{As} \quad\left(3 \cdot 10^{17} \mathrm{~cm}^{-3}\right)$, $1200 \mathrm{Hм} \mathrm{Al}_{0.48} \operatorname{In}_{0.52} \mathrm{As}\left(7 \cdot 10^{18} \mathrm{~cm}^{-3}\right)$, и верхний „Подконтактный“ сильно легированный 50 нм слой $\mathrm{Ga}_{0.47} \mathrm{In}_{0.53} \mathrm{As}\left(2 \cdot 10^{19} \mathrm{~cm}^{-3}\right)$. При выборе числа периодов мы руководствовались необходимостью обеспечения высокой квантовой эффективности, приемлемых порогов и температуры генерации, а также их достаточностью для достижения оптимальных характеристик [4,5].

\section{2. Постростовая обработка (processing)}

Процесс постростовой обработки состоял из последовательных технологических этапов, приводящих к получению мезаполосковой гребневой структуры (ridge waveguide). Формирование лазерных полосков в данной работе осуществлялось методом стандартной фотолитографии и жидкостного химического травления в травителе на основе $\mathrm{HBr}: \mathrm{H}_{2} \mathrm{O}_{2}(8: 1)$ со скоростью травления слоев структуры $\sim 3.2$ мкм/мин. Детальное рассмотрение способов травления подобной полосковой структуры в различных селективных и неселективных составах травителей было проведено нами ранее в работах $[5,6]$.

Предварительно выявлялась кристаллографическая ориентация химическим травлением подложки в ортофосфорной кислоте при температуре $85^{\circ} \mathrm{C}$. Затем формировали маску фоторезиста AZ 1518 шириной 30 мкм вдоль кристаллографического направления $\langle 110\rangle$. При травлении полоска, расположенного в этом направлении, боковая стенка вытравленного рельефа получается наиболее гладкой, с минимальным количеством дефектов. Глубина вытравленного полоска составляла $\sim 10$ мкм, а ширина в верхней части $\sim 17.5$ мкм.

Следующим этапом было формирование диэлектрического покрытия методом взрывной литографии. Для этого на вершину вытравленного полоска наносили маску фоторезиста AZ 4533 шириной 12 мкм, затем методом магнетронного нанесения осаждали двухслойное покрытие $\mathrm{TiO}_{2} / \mathrm{SiO}_{2}$ толщиной $\sim 0.2$ мкм, удаление фоторезиста осуществляли в диметилформамиде с последующей промывкой в деионизованной воде. Данный диэлектрик имеет прекрасные диэлектрические свойства и очень хорошую адгезию ко всем слоям, составляющим структуру. Утоньшение подложки InP до $\sim 120$ мкм проводилось химическим травлением в концентрированной соляной кислоте, которая обеспечивает высокую плоскопараллельность.

В качестве омического контакта к подложке использовали многослойное покрытие $\mathrm{AuGe} / \mathrm{Ni} / \mathrm{Au}$, осажденное методом вакуумного термического испарения, которое отжигалось в атмосфере водорода в течение 30 с при температуре $370^{\circ} \mathrm{C}$ на установке быстрого термоотжига (rapid thermo-annialing - RTA).

Для обеспечения надежной сборки дополнительно наносили слой $\mathrm{Cr} / \mathrm{Au}$ толщиной $\sim 0.2$ мкм. На лицевую сторону полоска в качестве омического контакта и коммутирующего слоя наносили слой $\mathrm{Cr} / \mathrm{Au}$ толщиной $\sim 0.4$ мкм, который не подвергали термообработке. Особенностью вакуумного термического осаждения является неравномерность нанесения металла на рельефную поверхность, из-за того что напыление осуществляется коллимированным потоком атомов. В результате толщина металла на вертикальной боковой стенке оказывается по крайней мере на порядок меньше, чем на горизонтальной поверхности. Для устранения этого недостатка коммутирующий слой утолщали методом дополнительного гальванического осаждения $\mathrm{Au}$ толщиной $\sim 0.2$ мкм, процесс проводили из стандартного цианистого электролита золочения в импульсном режиме осаждения. Полученная в результате гребневая полосковая структура показана на рис. 1 и 2 при разном увеличении в электронном микроскопе. Образцы раскалывались на чипы длиной 1-4 мм и напаивались на медный теплоотвод с использованием индиевого припоя.

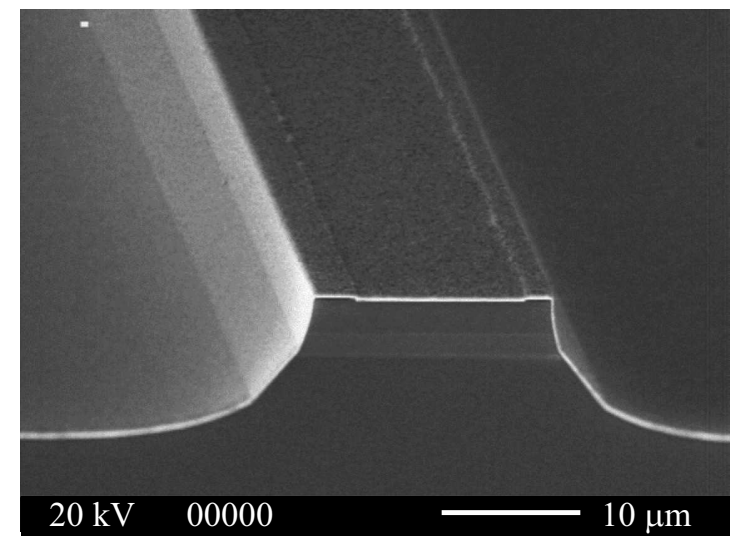

Рис. 1. Общий вид полосковой структуры (ridge waveguide) в электронном микроскопе.

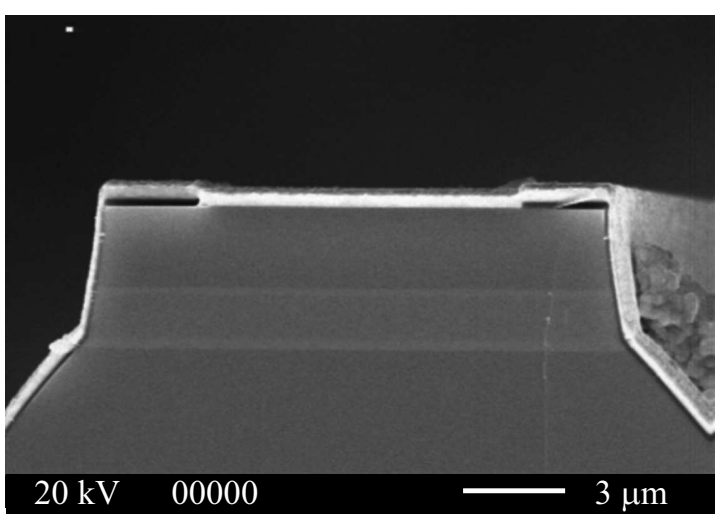

Рис. 2. Скол полученной в результате постростовой обработки полосковой гребневой структуры (ridge waveguide) с нанесенными диэлектриком и металлическим контактом при большем увеличении. 


\section{3. Обсуждение результатов}

Напайка полученных гребневых полосковых структур на теплоотвод проводилась двумя методами: либо подложкой, либо самой полосковой структурой на металл (индий). Второй способ предпочтительнее с точки зрения теплоотвода, но существенно сложнее технически.

На всех тестовых образцах была получена лазерная генерация. На рис. 3 представлены типичные вольтамперные характеристики лазерной структуры вместе с зависимостями интенсивности излучения от тока накачки для разных температур теплоотвода от 80 до $300 \mathrm{~K}$. Вольт-амперные характеристики являются характерными для вертикального транспорта в каскадных структурах и показывают общее падение напряжения на структуре в рабочем режиме, не превышающее $12 \mathrm{~B}$.

На изготовленной полосковой структуре, напаянной вверх полоском (подложкой на теплоотвод), была получена генерация до комнатной температуры на требуемой длине волны ( $\sim 4.8$ мкм), приведенная на рис. 3. Но спектр в таком варианте записать не удалось из-за перегрева образца (рис. 4).

Сравнение время-разрешенных спектров лазерной генерации образцов лазерных чипов, смонтированных на теплоотвод со стороны подложки и со стороны структуры, показало, что при питании лазерных чипов, смонтированных подложкой на теплоотвод, импульсами увеличенной длительности при рабочих токах происходит плавное смещение всего спектра излучения примерно на $1 \mathrm{~cm}$ за 0.5 мкс в длинноволновую область, что говорит о динамическом нагреве активной области и недостаточном теплоотводе в такой конфигурации.

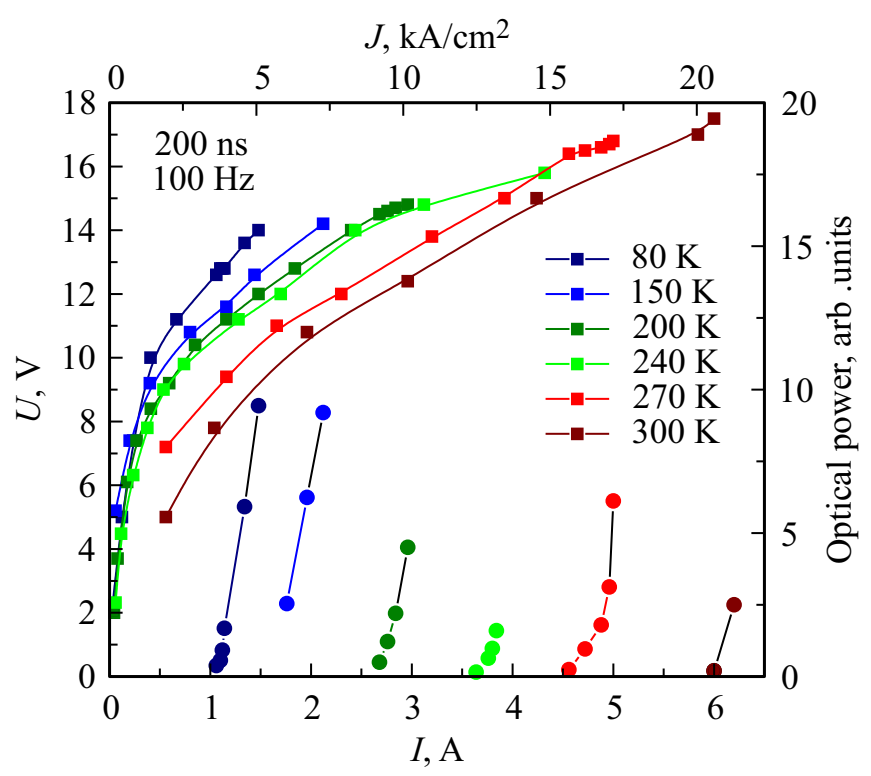

Рис. 3. Вольт-амперные и ватт-амперные характеристики полученной полосковой структуры при напайке подложкой на теплоотвод.

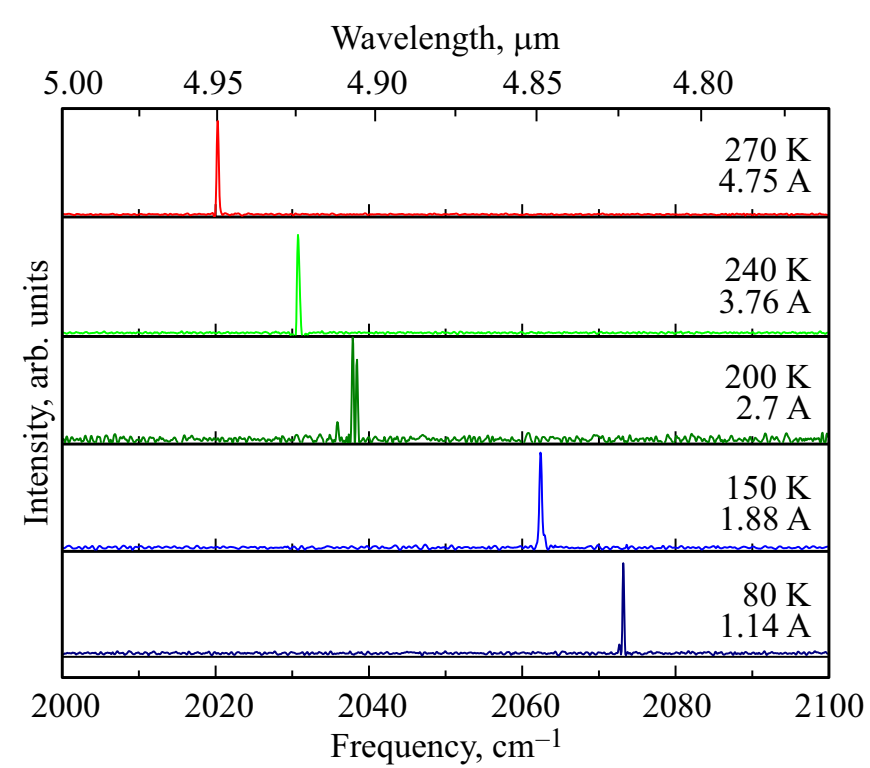

Рис. 4. Спектры генерации полученной полосковой структуры при напайке подложкой на теплоотвод.

Во втором варианте - вниз полоском - улучшенный теплоотвод позволил записать спектр лазерной генерации при комнатной температуре.

Таким образом, использование данной полосковой гребневой структуры и геометрии напайки структуры полоском на теплоотвод привело к достижению генерации на требуемой длине волны при комнатной температуре, что и являлось конечной целью нашей работы. Более подробно спектры генерации будут опубликованы в отдельной работе в журнале „Письма в ЖТФ“.

\section{4. Заключение}

Исследован процесс постростовой обработки и приготовления гребневой полосковой структуры (ridge waveguide) для квантового каскадного лазера с изорешеточными слоями на длину волны $\sim 4.8$ мкм, соответствующей окну прозрачности атмосферы. Изготовление лазерных полосков при соответствующей напайке их на теплоотвод сразу привело к достижению лазерной генерации при комнатной температуре, чего не удавалось достичь ранее [5] на той же гетероструктуре.

В эксперименте получена лазерная генерация при температурах вплоть до $300 \mathrm{~K}$ на длине волны, совпадающей с расчетной, что подтверждает высокое качество интерфейсов и прецизионную точность толщин и легирования активной области ККЛ, а также высокое качество диэлектрика и металлических контактов. Ведутся работы по оптимизации полосковой структуры и созданию улучшенного теплоотвода для улучшения лазерных характеристик.

Авторы выражают благодарность С.И. Трошкову за исследование образцов на электронном микроскопе. 


\section{Список литературы}

[1] В.В. Мамутин, В.М. Устинов, J. Boetthcher, Н. Kuenzel. ФТП, 44, 995 (2010).

[2] A. Tsecoun, R. Go, M. Pushkarsky, V. Razeghi, C.K.N. Patel. PNAS (Proc. Nat. Acad. Sci., USA), 103, 4831 (2006).

[3] M. Razeghi, S. Slivken, Y. Bai, B. Gokden, S.R. Darvish. New J. Phys., 11, 125017 (2009).

[4] C. Gmachl, F. Capasso, D.L. Sivco, A.Y. Cho. Rep. Prog. Phys., 64, 1533 (2001).

[5] В.В. Мамутин, А.П. Васильев, А.В. Лютецкий, Н.Д. Ильинская, Ю.М. Задиранов, А.Н. Софронов, Д.А. Фирсов, Л.Е. Воробьев, Н.А. Малеев, В.М. Устинов. ФТП, 52, 812 (2018).

[6] В.В. Мамутин, Н.Д. Ильинская, Б.В. Пушный, Р.В. Левин, Д.А. Бедарев. ФТП, 48, 1132 (2014).

Редактор Г.А. Оганесян

\section{Ridge waveguide structure for lattice matched quantum cascade lasers}

V.V. Mamutin, N.D. Ilyinskaya, A.A. Usikova, A.V. Lyutetskiy

loffe Institute,

194021 St. Petersburg, Russia

Abstract We have demonstrated MBE growth of lattice matched quantum cascade laser on the indium phosphide substrate with 30 cascades designed for $\sim 4.8 \mu \mathrm{m}$ wavelength for the atmospheric window in this spectral range. It was demonstrated the preparation of ridge waveguide laser structure for improving of thermoleakedge that allow us to achieve lasing up to room temperature. The lasing have demonstrated exactly the expected spectral line position that confirms high heterointerface quality and high precision control of the layer thicknesses and doping levels in the laser active region. 